\title{
KEBERLANJUTAN DAERAH PERLINDUNGAN LAUT BERBASIS MASYARAKAT \\ Kasus DPL-BM Blongko-Minahasa Selatan, DPL-BM Pulau Sebesi, Lampung Selatan dan APL Pulau Harapan Kepulauan Seribu ${ }^{1}$
}

\author{
Riana Faiza ${ }^{2}$, Tridoyo Kusumastanto ${ }^{3}$, Dietriech G. Bengen ${ }^{3}$, Mennofatria Boer ${ }^{3}$, \\ dan Fredinan Yulianda ${ }^{3}$. \\ ${ }^{2}$ Mahasiswa Program Studi SPL-IPB \\ Departemen Manajemen Sumberdaya Perairan, Fakultas Perikanan dan IImu Kelautan IPB \\ Kampus IPB Darmaga-Bogor, Telp./Fax. (0251) 624360 \\ Email : splipb@centrin.net.id \\ ${ }^{3}$ Komisi Pembimbing \\ Diterima 2 Maret 2010 - Disetujui 28 April 2010
}

\begin{abstract}
ABSTRAK
Tujuan umum dari penelitian ini adalah untuk mengevaluasi efektivitas perlindungan laut di tiga lokasi. Tujuan khususnya adalah (1) untuk mengevaluasi keberlanjutan dari perlindungan laut, dan (2) untuk merumuskan langkah strategis untuk pengembangan perlindungan laut. Penelitian dilakukan di tiga lokasi, yaitu Desa Blongko, Propinsi Sulawesi Utara, Pulau Sebesi, Provinsi Lampung, dan Pulau Harapan, Provinsi DKI Jakarta. Pengumpulan data dilakukan pada bulan Juni sampai Desember 2007. Metode analisis terdiri dari (1) analisa sumber daya alam dengan analisis kuantitatif, dan analisa keberlanjutan oleh scaling multi dimensi analisis. Ada 32 atribut telah dianalisa untuk mengevaluasi keberlanjutan perlindungan laut di tiga lokasi. Dengan analisis leverage ditemukan atribut-atribut dengan sensitivitas yang tinggi yaitu kualitas terumbu karang dan ikan karang (ekologi dan lingkungan dimensi); kontribusi pendapatan, mata pencaharian alternatif dan efek ganda dari perlindungan laut (aspek hukum ekonomi dan sosial dimensi);, peraturan daerah dan internalisasi program untuk program pembangunan daerah (dimensi kebijakan); pedoman perlindungan laut, program berkelanjutan, peningkatan kapasitas, dan partisipasi lembaga non pemerintah (dimensi kelembagaan).
\end{abstract}

Kata Kunci: efektivitas, keberlanjutan, manajemen strategi, daerah perlindungan laut

\section{Abstract : Sustainability of Community Based Management for Marine Protected Area :Cases of the DPL-BM Blongko-Minahasa Selatan, the DPL-BM Sebesi Island-Lampung Selatan and the APL Harapan Island-Kepulauan Seribu}

General objective of this research was to evaluate the effectiveness of marine sanctuaries in three locations. Specifically of this research were to evaluate the sustainability of marine sanctuary, and to formulate the strategic action for developing of marine sanctuary. Research was conducted at three locations, Blongko in North Sulawesi Province, Sebesi Island in Lampung Province, and Harapan Island, in Jakarta Province. Data collection was conducted during June to December 2007. This research used quantitative analysis by applying natural resources and sustainability analysis through multi dimension scaling analysis. This research applied 32 attributes to evaluate the sustainability of marine sanctuaries in three locations. By analysis of these attributes, it founded the attribute with high sensitivity remains to quality of coral reef and fish coral (ecological and environmental dimension); contribution of income, alternative livelihood and multiplier effect of marine sanctuary (economic and social dimension); legal aspect, local regulation and internalization of the program to local development program (policy dimension); and guidelines of marine sanctuary, extension officer programs and capacity building, and participation of non government institution (institutional dimension).

\section{Keywords: effectivitaly, sustainability, management strategy, marine protected area}

${ }^{1}$ Bagian dari disertasi berjudul Efektivitas dan Keberlanjutan Daerah Perlindungan

Laut Berbasis Masyarakat: kasus DPL-BM Blongko, Minahasa Selatan, DPL-BM Pulau Sebesi,

Lampung Selatan dan APL Pulau Harapan, Kepulauan Seribu 


\section{PENDAHULUAN}

Daerah Perlindungan Laut Berbasis Masyarakat (DPL-BM) merupakan pendekatan yang umum diterapkan pada program pengelolaan sumberdaya pesisir dan laut di dunia, terutama di negara yang memiliki ekosistem terumbu karang. Daerah perlindungan laut dapat dianggap sebagai manifestasi dari keinginan masyarakat untuk memenuhi kebutuhannya, seperti kebutuhan untuk memanfaatkan sumber daya alam secara lestari, kebutuhan untuk menikmati keindahan alam.

Daerah perlindungan laut berbasis masyarakat merupakan upaya masyarakat untuk mempertahankan dan memperbaiki kualitas sumber daya ekosistem terumbu karang dan sekaligus mempertahankan dan meningkatkan kualitas sumber daya lainnya yang berasosiasi dengan terumbu karang. Pengembangan daerah perlindungan laut di Indonesia pertama kali diinisiasi oleh Program Coastal Resources Management Project (CRMP) atau lebih populer disebut Proyek Pesisir pada 1996 di Kabupaten Minahasa Selatan Provinsi Sulawesi Utara.

Konsep DPL ini kemudian diadopsi oleh program yang sama di Pulau Sebesi, Kabupaten Lampung Selatan, Provinsi Lampung pada tahun 2001. Saat ini DPL juga sudah mulai dikembangkan oleh Pemerintah Kabupaten Administrasi Kepulauan Seribu, Provinsi DKI Jakarta yang dikenal dengan nama Area Perlindungan Laut (APL). Alasan peneliti memilih tiga lokasi ini karena DPL Pulau Blongko mewakili DPL di pulau besar, DPL Pulau Sebesi mewakili DPL di pulau-pulau kecil dan APL Pulau Harapan mewakili DPL di Pulau-pulau sangat kecil.

Tujuan penelitian adalah (2) mengevaluasi keberlanjutan pengembangan daerah perlindungan laut berbasis masyarakat; dan (2) merumuskan strategi pengembangan daerah perlindungan laut berbasis masyarakat.

\section{METODOLOGI}

\section{Waktu dan Lokasi Penelitian}

Penelitian dilakukan selama 12 bulan yaitu dari bulan Juni 2007 - Mei 2008. Penelitian dilakukan di 3 lokasi, yaitu (1) DPL Desa Blongko, Kabupaten Minahasa Selatan -Provinsi Sulawesi Utara, (2) DPL Desa Tejang Pulau Sebesi, Kabupaten Lampung Selatan Provinsi Lampung, dan (3) APL Pulau Harapan, Kabupaten Administrasi Kepulauan Seribu - Provinsi DKI Jakarta. (Gambar 1)

\section{Metode Pengumpulan Data}

Data yang dikumpulkan tediri dari data primer dan sekunder. Data sekunder diperoleh dari berbagai institusi terkait dan penelusuran berbagai pustaka. Data primer dikumpulkan melalui observasi, wawancara, diskusi, dan pengukuran di lapang.

\section{(1) Data Ekologi/Biologi-Fisik}

Data biofisik yang dikumpulkan meliputi data oseanografi, kualitas air dan sumber daya hayati laut. Parameter oseanografi dan kualitas air yang diukur secara langsung di lapangan meliputi suhu, kecerahan, kecepatan arus, salinitas, kekeruhan, derajat keasaman $(\mathrm{pH})$. Data biologi dan sumber daya hayati yang dikumpulkan meliputi terumbu karang, mangrove, lamun dan sumberdaya perikanan.

\section{(2) Data Sosial Ekonomi dan Budaya}

Data sosial ekonomi meliputi jumlah penduduk, mata pencaharian, pendidikan, persepsi, partisipasi masyarakat dalam pengelolaan sumberdaya pesisir, kecenderungan masyarakat memanfaatkan sumberdaya laut dan sebagainya, serta keinginan masyarakat. Data kelembagaan meliputi lembaga-lembaga yang ada di tingkat desa (formal dan non formal), kapasitas lembaga, program yang dibuat oleh lembaga yang ada, dan sebagainya. Peraturan dan perundangan meliputi seluruh peraturan dan perundangan baik pada level desa, kecamatan, kabupaten maupun propinsi, baik 


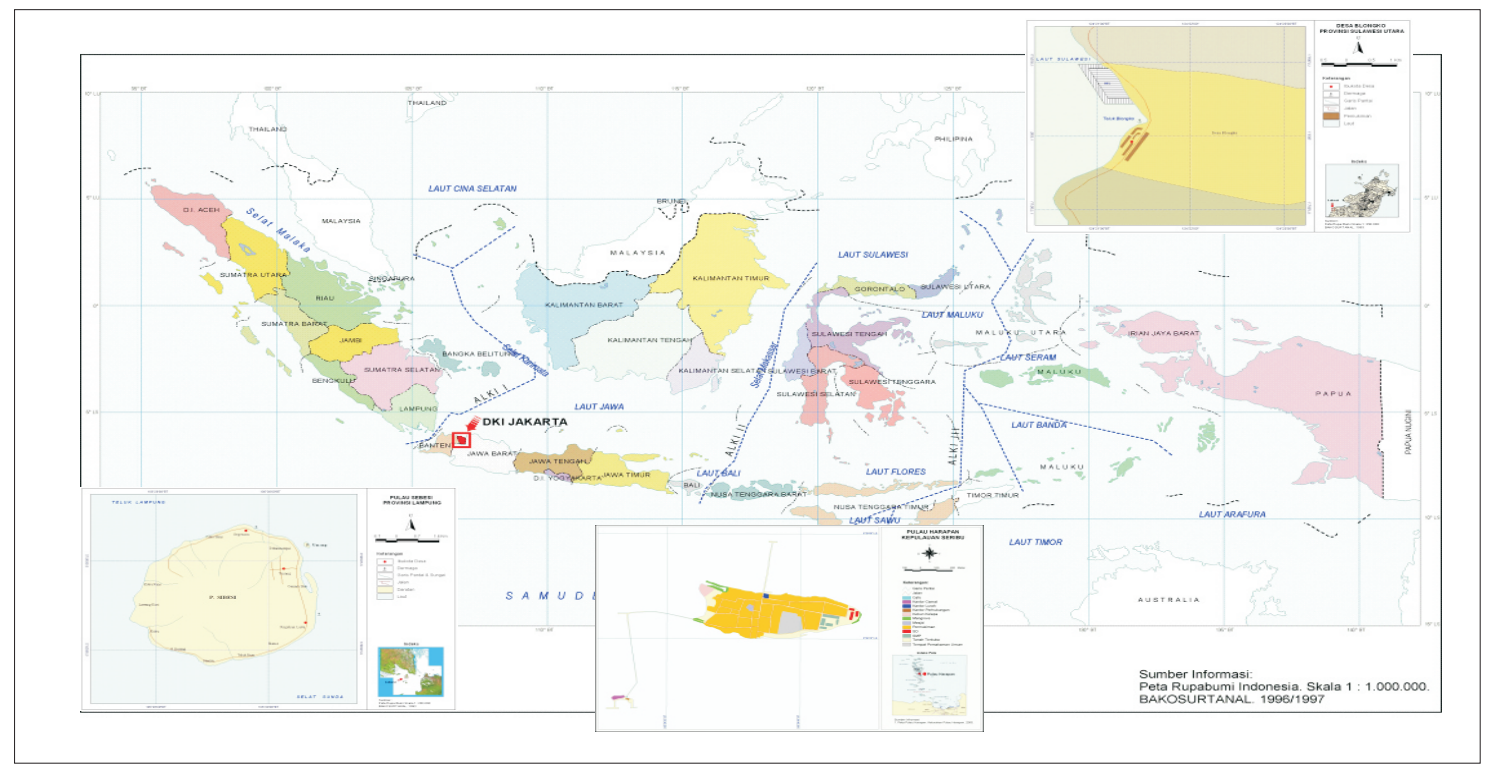

Gambar1. Peta Lokasi Penelitian (DPL Desa Blongko, Kabupaten Minahasa SelatanProvinsi Sulawesi Utara, DPL Pulau Sebesi, Kabupaten Lampung SelatanProvinsi Lampung, dan APL Pulau Harapan, Kabupaten Administrasi Kepulauan Seribu-Provinsi DKI Jakarta)

Picture 1. Research Location Map (MPA Blongko Village, Minahasa District-North Sulawesi Province, MPA Sebesi Island, South Lampung District-Lampung Province and MPA Harapan Island, Kepulauan Seribu Administrative District-DKI Jakarta Province)

secara langsung maupun tidak langsung mendukung pengembangan daerah perlindungan laut.

\section{Metode Analisis Data}

\section{(1) Penentuan Parameter Penilaian}

Fokus analisis keberlanjutan DPL untuk mengetahui sejauh mana program DPL di lokasi penelitian dapat dilanjutkan oleh masyarakat setempat. Ketiga DPL yang diteliti merupakan program inisiasi oleh pihak luar. Sehingga dalam jangka waktu tertentu inisiator tidak lagi terlibat baik langsung maupun tidak langsung. Dengan demikian, tanggungjawab selanjutnya untuk melanjutkan program ini adalah masyarakat setempat. Apakah masyarakat akan melanjutkan program ini atau tidak, terdapat banyak faktor yang mempengaruhinya. Faktor yang mempanguruhi keberlanjutan daerah perlindungan laut di tiga lokasi penelitian, dapat dikelompokkan menjadi empat kategori, yaitu aspek ekologi dan lingkungan, sosial ekonomi dan budaya, kebijakan setempat dan hukum dan kelembagaan.

\section{(2) Teknik Analisis Data}

Teknik analisis pengolahan data menggunakan program RAPFISH yang dimodifikasi. Tahapan pengolahan data RAPFISH adalah sebagai berikut:

1. Menentukan nilai bobot/ scoring

2. Menentukan atribut

3. Menentukan referensi/ Good, Bad, Up and Down

4. Menentukan anchor/

Untuk mensintesis tingkat keberlanjutan pengelolaan DPL, digunakan tiga kategori,dapat dilihat dari Tabel 1. 
Tabel 1. Kategori Penilaian Keberlanjutan Pengelolaan DPL

Table 1. Sustainability Assessment Category of MPA Management

\begin{tabular}{|c|c|c|c|}
\hline No. & $\begin{array}{l}\text { Skala Keberlanjutan } \\
\text { ISustainable Scale }\end{array}$ & $\begin{array}{l}\text { Kategori } \\
\text { /Category }\end{array}$ & $\begin{array}{l}\text { Keterangan } \\
\text { IInformation }\end{array}$ \\
\hline 1. & $0,00-33,33$ & $\begin{array}{l}\text { Rendah } \\
\text { /Low }\end{array}$ & $\begin{array}{l}\text { DPL dengan kategori ini memiliki peluang } \\
\text { sangat kecil untuk berkembang lebih lanjut. } \\
\text { IMPA with this catagory has very little } \\
\text { opportunity to develop further }\end{array}$ \\
\hline 2. & $33,34-66,66$ & $\begin{array}{l}\text { Sedang } \\
\text { /Midle }\end{array}$ & $\begin{array}{l}\text { DPL ini akan berkelanjutan, namun tidak } \\
\text { memberikan hasil optimal atau dengan kata } \\
\text { lain ada beberapa tujuan yang tidak tercapai } \\
\text { /This MPA has sustainability, but does not } \\
\text { provide optimum results, or in other words, } \\
\text { there are some objectives are not met }\end{array}$ \\
\hline 3. & $66,67-100,00$ & $\begin{array}{l}\text { Tinggi } \\
\text { /High }\end{array}$ & $\begin{array}{l}\text { DPL ini berkelanjutan, memberikan hasil } \\
\text { optimal dan tujuan pengembangan DPL tercapai }\end{array}$ \\
\hline & & & $\begin{array}{l}\text { IThis MPA is ongoing, provides optimal results } \\
\text { and achieve the goal of developing DPL }\end{array}$ \\
\hline
\end{tabular}

Sumber: Modifikasi dari Susilo (2003)/Source:Modified from Susilo (2003).

\section{HASIL DAN PEMBAHASAN}

Penilaian keberlanjutan DPL didasarkan pada Indeks Keberlanjutan DPL (IB-DPL). IBDPL tertinggi dimiliki oleh DPL Pulau Sebesi, yaitu 72,41 pada skala keberlanjutan $0-100$. DPL Desa Blongko memiliki nilai IB-DPL sebesar 63,83. Adapun APL Pulau Harapan memiliki Indeks Keberlanjutan sebesar 36,30.

Hasil penilaian terhadap 32 atribut yang terdiri dari 4 aspek atau dimensi, yaitu aspek ekologi dan lingkungan, sosial ekonomi dan budaya, kebijakan setempat, dan kelembagaan memperlihatkan bahwa Program DPL Pulau Sebesi dan DPL Desa Blongko memiliki prospek keberlajutan yang tinggi (di atas 50) seperti yang disebutkan oleh Susilo (2003).

Dari hasil analisis di atas, dapat dikatakan bahwa program DPL Pulau Sebesi dan Desa Blongko memiliki prospek keberlanjutan yang lebih tinggi untuk terus dikembangkan oleh masyarakat, dibandingkan program APL Pulau Harapan, dimana nilai IB-DPL kurang dari 50 pada skala 0-100 (Gambar 2).

Hal ini tentunya harus menjadi perhatian bagi inisiator program, jika ingin program ini terus berlanjut. Untuk program DPL Desa Blongko dan Pulau Sebesi juga perlu dikaji lebih lanjut, aspek apa saja yang belum berkelanjutan dari pengembangan DPL di dua lokasi ini.

Hasil penilaian Indeks Keberlanjutan Pengembangan 3 DPL yang diteliti sebagaimana disajikan pada Tabel 2 menunjukkan bahwa IB-DPL ditinjau dari aspek ekologi dan lingkungan dari 3 DPL yang diteliti umumnya sudah tinggi, yaitu di atas nilai 50 pada skala $0-100$. Nilai IB-DPL yang sangat tinggi dari aspek ekologi dan lingkungan pada program DPL Pulau Sebesi, yaitu mencapai 87,74. Nilai IB-DPL Desa Blongko juga cukup tinggi, yaitu 83,28. Nilai IB-DPL terendah terdapat pada APL Pulau Harapan. Hal ini sesuai dengan hasil yang diperlihatkan dari setiap atribut yang sudah dijelaskan. Dimana DPL Pulau Sebesi dan DPL Blongko memiliki nilai yang cenderung maksimum dibandingkan dengan program APL Pulau Harapan. Dari hasil analisis leverage atribut diketahui bahwa atribut yang paling berpengaruh terhadap keberlanjutan ditinjau dari aspek ekologi dan lingkungan adalah kualitas ikan karang, kualitas terumbu 
Tabel 2. Nilai Indeks Keberlanjutan Pengembangan DPL Desa Blongko, Pulau Sebesi dan APL Pulau Harapan

Table 2. Sustainable Index Value of MPA Development Blongko Village, Sebesi Island and Harapan Island

\begin{tabular}{lccc}
\hline \multirow{2}{*}{ Dimensi/Dimension } & \multicolumn{3}{c}{ Lokasi DPL/ MPA Location } \\
\cline { 2 - 4 } & DPL Blongko & DPL Pulau Sebesi & APL Pulau Harapan \\
\hline Ekologi/Ecology & 83,28 & 87,74 & 52,89 \\
Ekonomi dan Budaya/ & 54,28 & 65,18 & 24,62 \\
$\begin{array}{l}\text { Economic and Culture } \\
\text { Kebijakan Setempat/ }\end{array}$ & 57,22 & 60,25 & 25,26 \\
$\begin{array}{l}\text { Local Policy } \\
\text { Kelembagaan/ }\end{array}$ & 65,47 & 82,29 & 49,09 \\
Institutional & & & \\
Total & $\mathbf{6 3 , 8 3}$ & $\mathbf{7 2 , 4 1}$ & $\mathbf{3 6 , 3 0}$ \\
\hline
\end{tabular}

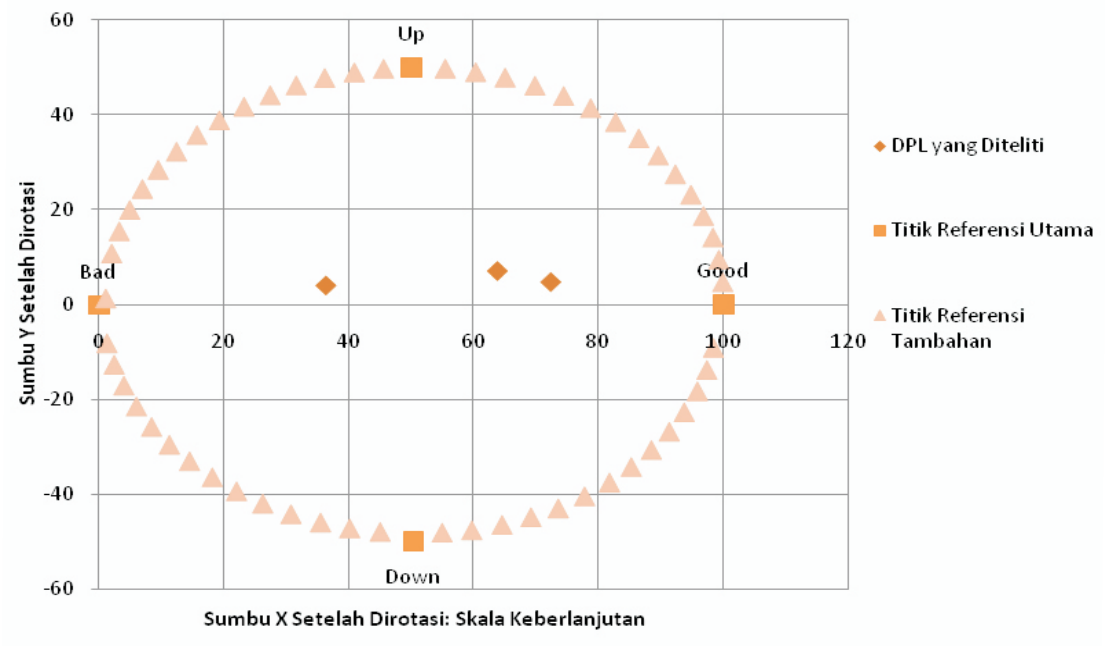

Gambar 2. Posisi Keberlanjutan Pengembangan Program DPL Desa Blongko, Pulau Sebesi dan Pulau Harapan

Picture 2. Sustainable Position of Program Development MPA Blongko Village, Sebesi Island and Harapan Island

karang, penggunaan alat tangkap destruktif seperti cyanide dan alat tangkap dasar. Keempat atribut inilah yang mempengaruhi prospek keberlanjutan pengembangan daerah perlindungan laut.

Dimensi sosial ekonomi dan budaya memiliki nilai IB-DPL yang terendah jika dibandingkan dengan nilai IB-DPL tiga dimensi lainnya. APL Pulau Harapan memiliki nilai IB-DPL yang sangat rendah, yaitu kurang dari 50 (24,62). DPL Blongko dan Pulau Sebesi masih memiliki nilai IB-DPL yang tinggi, yaitu masing-masing 54,28 dan 65,18. Namun jika dibandingkan dengan nilai IB-DPL 
untuk aspek ekologi dan lingkungan masih jauh lebih rendah. Hal ini menunjukkan bahwa dampak dari program DPL terhadap atributatribut yang menyangkut aspek sosial ekonomi dan budaya masih rendah. Analisis leverage atribut untuk aspek sosial ekonomi dan budaya menunjukkan bahwa atribut yang mempengaruhi keberlanjutan pada aspek ini adalah penyerapan tenaga kerja, peningkatan pendapatan, efek ganda dari pengembangan DPL, serta pengembangan mata pencaharian alternatif.

Dilihat dari kesesuaian program DPL dengan aspek kebijakan setempat, nilai IB-DPL tidak berbeda jauh dengan nilai IB-DPL pada aspek sosial ekonomi dan budaya. Nilai IBDPL terendah untuk aspek kebijakan setempat terdapat pada pengembangan program APL Pulau Harapan sebesar 25,26. DPL Desa Blongko dan DPL Pulau Sebesi masing-masing 57,22 dan 60,25 . Nilai IB-DPL yang rendah ini menunjukkan bahwa atribut-atribut dari aspek kesesuaian program DPL dengan kebijakan setempat banyak yang belum optimal dikelola. Hal ini berarti bahwa untuk mempertahankan keberlanjutan program DPL di lokasi penelitian aspek ini perlu mendapatkan perhatian. Kesesuaian dengan kebijakan setempat dan adanya dukungan dari berbagai elemen masyarakat akan mendorong pengembangan DPL ini. Sebaliknya, jika tidak ada dukungan dari elemen masyarakat, maka DPL ini akan sulit berkembang. Atribut yang berpengaruh terhadap pengembangan DPL dilihat dari aspek kebijakan setempat adalah dukungan Peraturan Daerah (PERDA), dukungan program pemerintah daerah, dukungan lembaga non pemerintah, dan internalisasi program DPL kedalam program pemerintah daerah. Adanya dukungan Perda akan memberikan kekuatan hukum bagi pengembangan DPL ini. Demikian juga, jika program DPL diinternalisasikan ke dalam program tahunan, akan mendapatkan bantuan

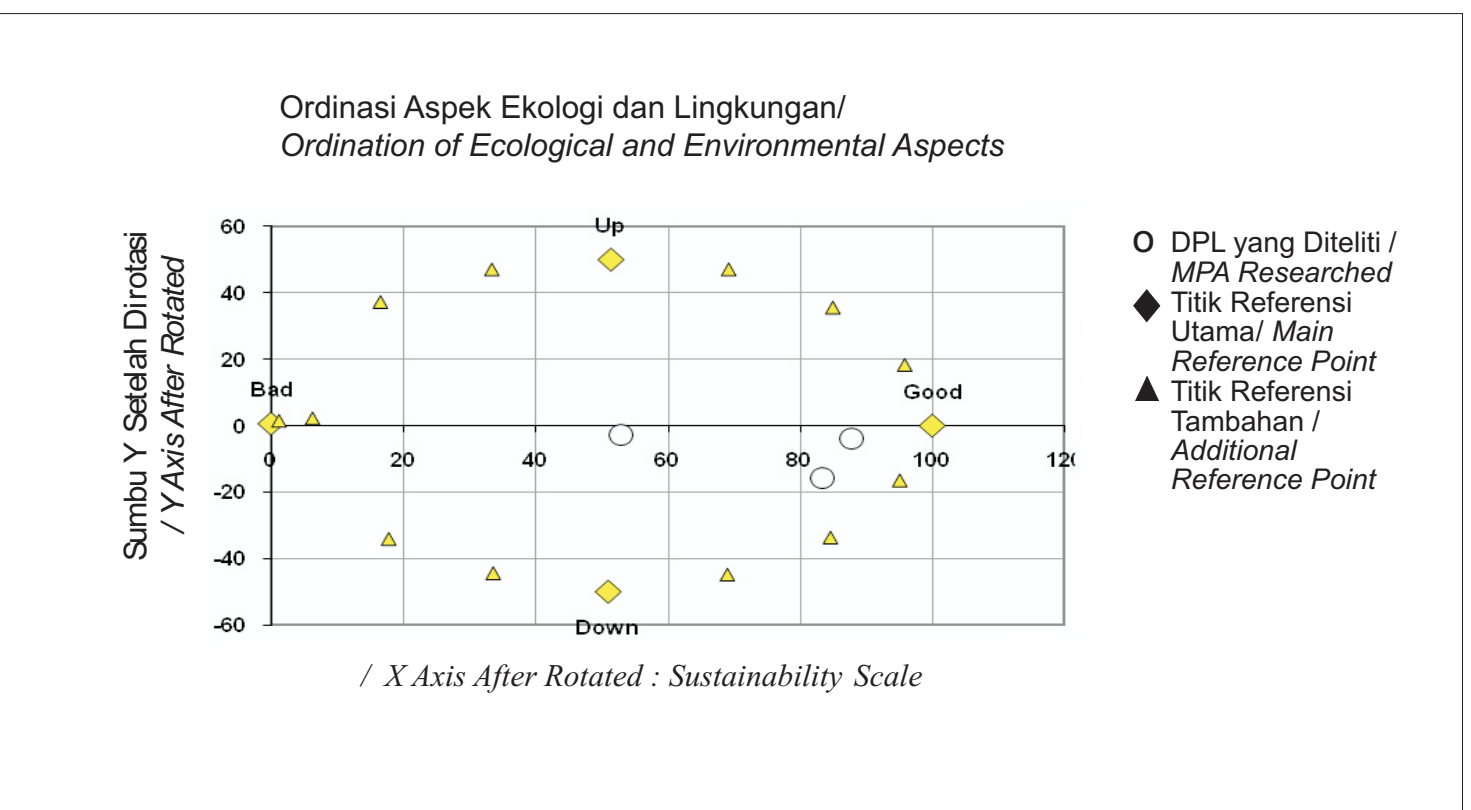

Gambar 3. Posisi Keberlanjutan Pengembangan Program DPL Desa Blongko, Pulau Sebesi dan Pulau Harapan Untuk Aspek Ekologi dan Lingkungan

Picture 3. Sustainable Position of Program Development MPA Blongko Village, Sebesi Island and Harapan Island for Ecological and Environmental Aspects 
Ordinasi Aspek Ekologi dan Lingkungan/

Ordination of Ecological and Environmental Aspects

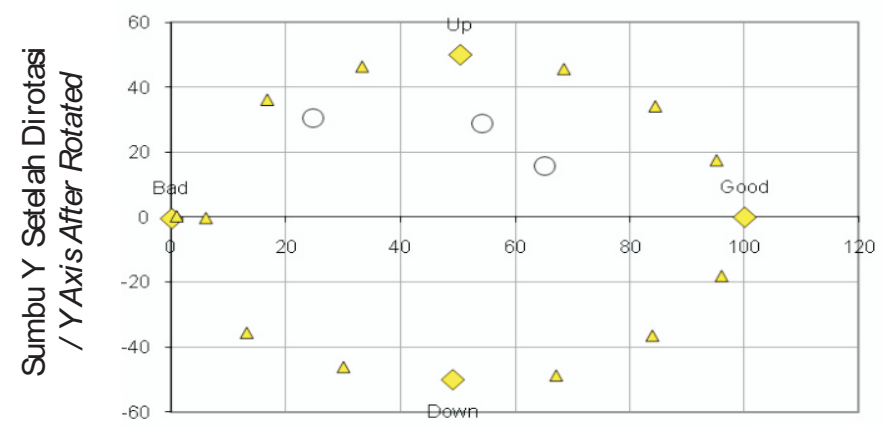

O DPL yang Diteliti / MPA Researched

Titik Referensi Utama/ Main Reference Point

$\Delta$ Titik Referensi Tambahan / Additional Reference Point

I X Axis After Rotated : Sustainability Scale

Gambar 4. Posisi Keberlanjutan Pengembangan Program DPL Desa Blongko, Pulau Sebesi dan Pulau Harapan Untuk Aspek Sosial Ekonomi dan Budaya

Picture 4. Sustainable Position of Program Development MPA Blongko Village, Sebesi Island and Harapan Island for Economic Social and Cultural Aspects

Ordinasi Aspek Ekologi dan Lingkungan/

Ordination of Ecological and Environmental Aspects

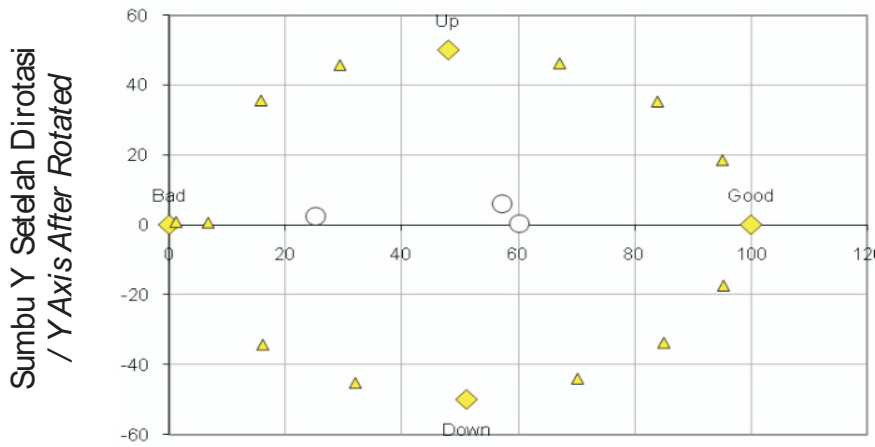

O DPL yang Diteliti / MPA Researched

Titik Referensi Utama/ Main Reference Point

$\Delta$ Titik Referensi Tambahan / Additional Reference Point

I X Axis After Rotated: Sustainability Scale

Gambar 5. Posisi Keberlanjutan Pengembangan Program DPL Desa Blongko, Pulau Sebesi dan Pulau Harapan Untuk Aspek Kebijakan Setempat

Picture 5. Sustainable Position of Program Development MPA Blongko Village, Sebesi Island and Harapan Island for Local Policy Aspects 
Ordinasi Aspek Ekologi dan Lingkungan/

Ordination of Ecological and Environmental Aspects
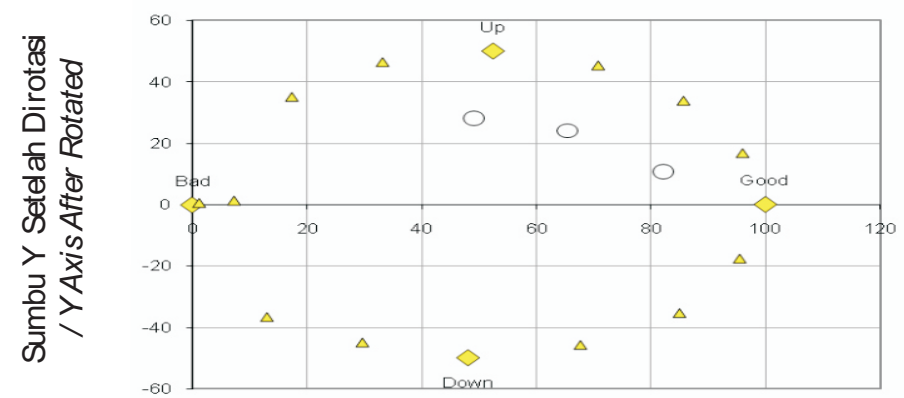

O DPL yang Diteliti / MPA Researched

Titik Referensi Utama/ Main Reference Point

A Titik Referensi

Tambahan /

Additional

Reference Point

I X Axis After Rotated : Sustainability Scale

\section{Gambar 6. Posisi Keberlanjutan Pengembangan Program DPL Desa Blongko, Pulau Sebesi dan Pulau Harapan Untuk Aspek Hukum dan Kelembagaan}

Picture 6. Sustainable Position of Program Development MPA Blongko Village, Sebesi Island and Harapan Island for Legal and Institutional Aspects

setiap tahun bagi pengembangan DPL.

Nilai IB-DPL untuk aspek kelembagaan dari tiga lokasi yang diteliti menunjukkan nilai yang lebih tinggi dari nilai IB-DPL untuk aspek sosial ekonomi-budaya dan aspek kebijakan setempat. Nilai IB-DPL tertinggi terlihat pada Program DPL Pulau Sebesi, yaitu 82,29. Nilai IB-DPL untuk DPL Desa Blongko dan APL Pulau Harapan masing-masing adalah 65,47 dan 49,09. Berdasarkan uraian setiap parameter yang telah dipaparkan sebelumnya, atribut yang membedakan ketiga lokasi ini adalah dalam hal pengembangan SDM dan legalitas dari program DPL. Untuk dua atribut ini, pada program DPL Pulau Sebesi dan Desa Blongko dikembangkan dengan baik, sedangkan pada program APL Pulau Harapan belum berjalan dengan baik. Empat atribut yang berpengaruh pada pengembangan DPL dilihat dari aspek kelembagaan adalah program pendampingan, bantuan dari pihak swasta/non pemerintah, program pelatihan dan aturan pengelolaan. Aspek kelembagaan dan pengembangan sumberdaya manusia sangat berpengaruh dalam pengembangan DPL. Analisis leverage menyajikan beberapa atribut yang sensitif terhadap keberlanjutan pengembangan daerah perlindungan laut (Gambar 7). Atribut sensitif untuk aspek ekologi dan lingkungan adalah perbaikan ekosistem terumbu karang, penurunan tekanan pemanfaatan terumbu karang, peningkatan keragaman ikan karang, dan program perlindungan sumberdaya.

Atribut sensitif aspek sosial ekonomi dan budaya adalah kontribusi terhadap peningkatan pendapatan masyarakat, penyerapan tenaga kerja, efek ganda, dan upaya pengembangan mata pencaharian alternatif. Untuk aspek kebijakan setempat, atribut yang sensitif adalah legalitas DPL, dukungan Peraturan Daerah (PERDA), dukungan program pemerintah daerah, dan internalisasi program DPL kedalam program 

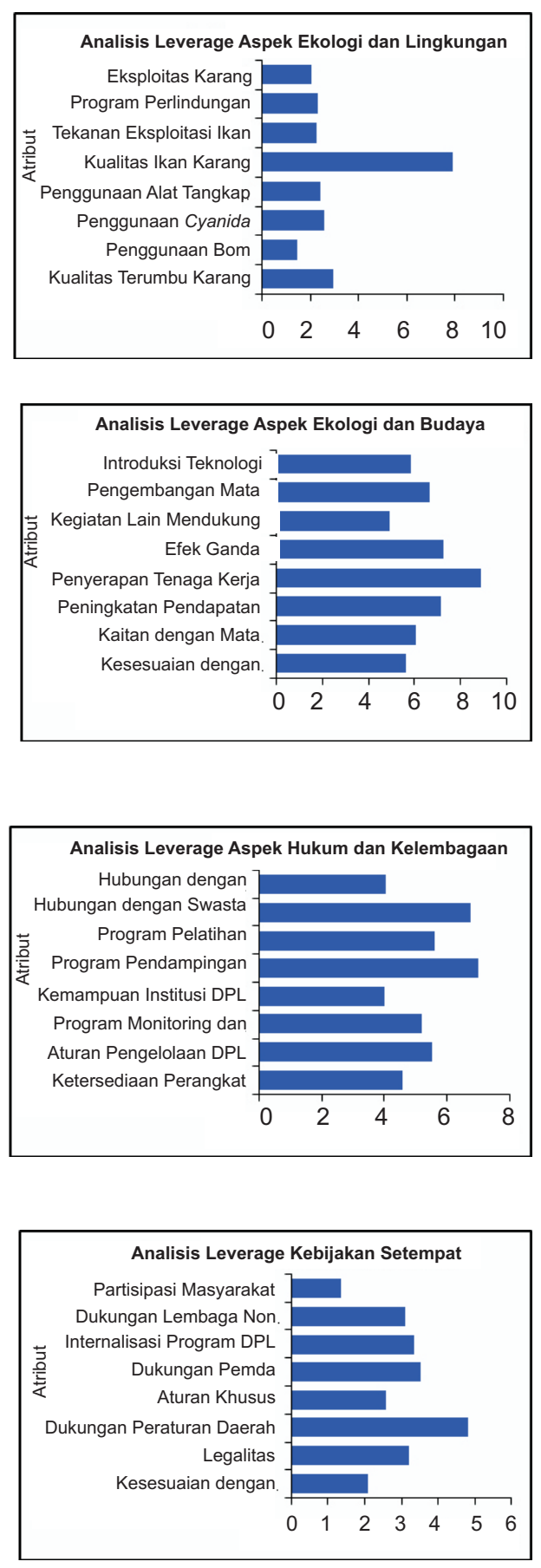
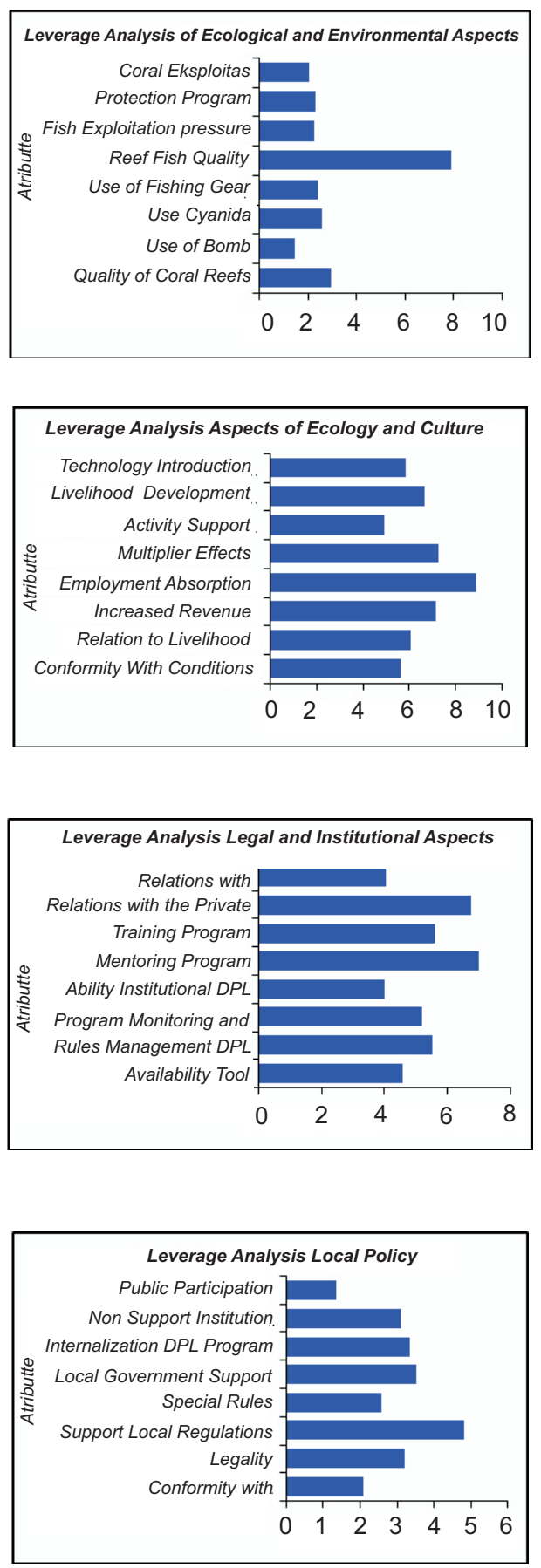

Gambar 7. Diagram Leverage Keberlanjutan Daerah Perlindungan Laut Picture 7. Leverage Diagram of Marine Protected Areas Sustainability 


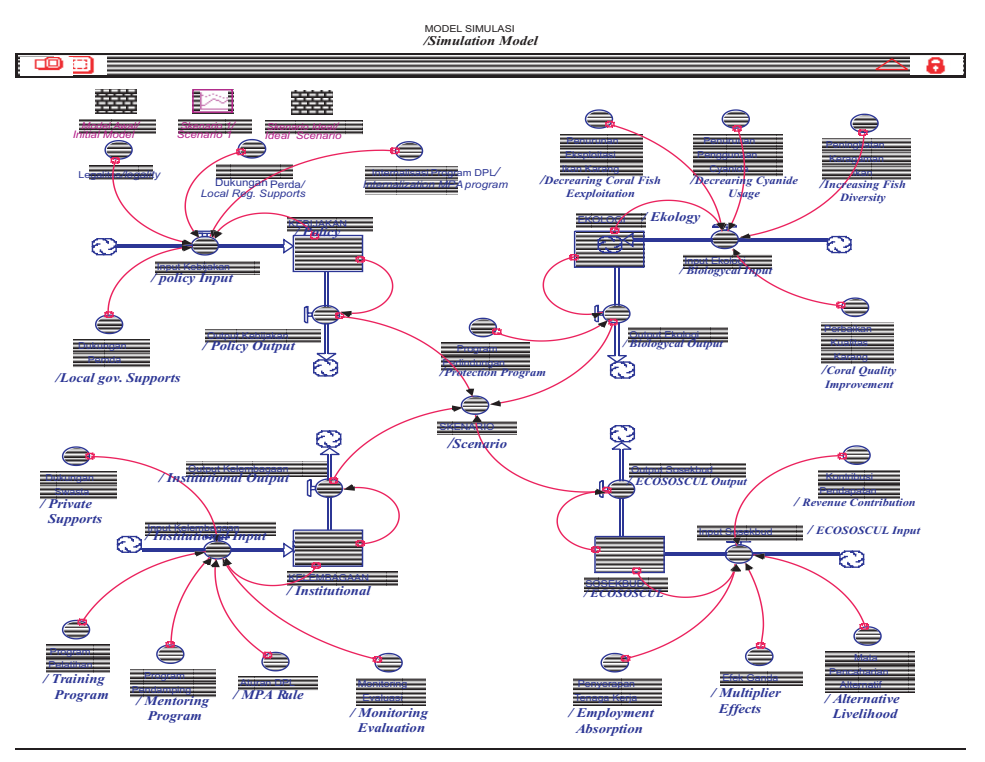

Gambar 8. Diagram konseptual Perumusan Konsep Keberlanjutan Pengembangan DPL Picture 8. Conceptual Diagram of Concept Formulation of Sustainability MPA Development

pembangunan daerah. Adapun aspek sensitif untuk aspek kelembagaan adalah aturan pengelolaan DPL, program pendampingan, program pelatihan, hubungan dengan lembaga donor, dan monitoring dan evaluasi. Secara diagramatik, konsep keberlanjutan pengembangan DPL disajikan pada Gambar 8.

\section{KESIMPULAN DAN IMPLIKASI KEBIJAKAN}

\section{Kesimpulan}

1. Tingkat keberlanjutan (IB-DPL) program DPL Desa Blongko dan DPL Pulau Sebesi sudah tinggi, yaitu di atas nilai IB-DPL 50 pada skala 0-100. Adapun APL Pulau Harapan masih rendah, yaitu kurang dari 50. Nilai indeks keberlanjutan berdasarkan aspek/dimensi adalah:

- Ekologi dan lingkungan: DPL Blongko $(83,28)$; DPL Sebesi $(87,74)$ dan APL Harapan $(52,89)$

- Sosial Ekonomi dan Budaya: DPL Blongko $(54,28)$; DPL Sebesi $(65,18)$; dan APL Harapan $(24,62)$
- Kebijakan: DPLBlongko $(57,22)$; DPL Sebesi $(60,25)$; dan APL Harapan $(25,26)$

- Kelembagaan: DPL Blongko $(65,47)$; DPL Sebesi (82,29); dan APL Harapan $(49,09)$

2. Strategi pengelolaan yang dapat dilakukan untuk menjaga keberlanjutan pengembangan DPLadalah:

- Peningkatan kualitas terumbu karang dan sumberdaya ikan di kawasan DPL melalui penekanan kegiatan yang merusak lingkungan.

- Pengembangan mata pencaharian alternatif guna mendukung program DPL sehingga dapat menciptakan lapangan pekerjaan bagi masyarakat.

- Internasilisasi program DPL ke dalam program tahunan pemerintah daerah, sehingga program ini mendapatkan perhatian secara kontinyu.

- Pelibatan lembaga lain (non pemerintah) dalam pengembangan DPL, sehingga berbagai keterbatasan 
yang dimiliki oleh masyarakat dan pemerintah daerah dapat diatasi.

3. Berdasarkan perbandingan ketiga DPL yang diteliti, DPL Pulau Sebesi memiliki tingkat kerbelanjutan yang lebih baik disusul DPL Blongko, kemudian APL Pulau Harapan.

\section{Implikasi Kebijakan}

1. Perlu dikaji aspek sosial ekonomi dan budaya lebih lanjut, mengapa aspek ini yang merupakan salah satu tujuan dari program pengembangan DPL ini umumnya masih rendah, dibandingkan dengan aspek ekologi dan lingkungan. Padahal, aspek ini sangat mempengaruhi keberlajutan program yang dikembangkan dengan pendekatan pengelolaan berbasis masyarakat.

2. Melihat tiga contoh program DPL yang diteliti, terlihat bahwa DPL Desa Blongko dan Pulau Sebesi memiliki tingkat keberlajutan yang lebih tinggi dari APL Pulau Harapan. Jika dilihat dari inisiator masing-masing program, dimana program DPL Desa Blongko dan DPL Pulau Sebesi diinisiasi oleh lembaga non pemerintah dengan pendekatan yang sangat partisipatif, sedangkan APL Pulau Harapan diinisiasi oleh pemerintah daerah dengan pendekatan proyek. Diperlukan kajian lebih lanjut untuk membuktikan bahwa program dengan pendekatan yang partisipatif akan lebih berkelanjutan dibandingkan dengan pendekatan proyek.

\section{DAFTAR PUSTAKA}

Alcala, A.C. 1998. Effect of Marine Reserve on Coral Fish Abundance and Yields on Philipina Coral Reefs. Ambio.

Arifin, T. 2008. Akuntabilitas dan Keberlanjutan Pengelolaan Kawasan Terumbu Karang di Selat Lembeh, Kota Bitung. Sekolah Pascasarjana-Institut Pertanian Bogor., Bogor
Bengen D.G, Tahir A, Wiryawan B. 2003. Tinjauan Sustainabilitas, Akuntabilitas, Replikabilitas, Pengembangan Daerah Perlindungan Laut di Pulau Sebesi, Lampung Selatan, Provinsi Lampung. Proyek Pesisir., Jakarta

Dinas Peternakan, Perikanan dan Kelautan DKI Jakarta. 2006. Pengelolaan dan Pengembangan Kawasan Konservasi Laut (KKL) di DKI Jakarta. Dinas Peternakan, Perikanan dan Kelautan DKI Jakarta dan PT. Coastmar Lestari., Jakarta

Hair, J.F. Anderson R.E, Tatham R.L, Black WC. 1998. Multivariate Data Analysis Fifth edition. Prentice Hall International, Inc. : New York

Hawis M.H, Alhusna I.S, Dahl-Tacconi $N$, Sihombing R, Setiawan F, Gunawan A, Muzahar NA, Ohoiulun H. 2005. Evaluasi Keefektifan Pengelolaan Daerah Perlindungan Laut Pulau Sebesi 20022004 dan Rekomendasi-rekomendasi untuk Meningkatkan Pengelolaan. NOAA (National Oceanic and Atmospheric Administration), BPDPL (Badan Pengelolaan Daerah Perlindungan Laut, Pulau Sebesi) dan PKSPL-IPB (Pusat Kajian Sumberdaya Pesisir dan Lautan, Institut Pertanian Bogor)., Bogor

Muttaqim, E., 2005.Kondisi Ekosistem Terumbu Karang Pada Tahun 2002 dan Tahun 2005 di Daerah Perlindngan Laut Pulau Sebesi Lampung. Fakultas Perikanan dan IImu Kelautan-Institut Pertanian Bogor., Bogor.

Partnership for Interdisciplinary Studies of Coastal Oceans, 2008. Ecosystem Responses in a Marine Reserve. diakses http://www.piscoweb.org/outreach/topics Impa.

Susilo, S.B. 2003. Keberlanjutan Pembangunan Pulau-Pulau Kecil: Studi Kasus Kelurahan Pulau Panggang dan Pulau Pari, Kepulauan Seribu, DKI Jakarta. Sekolah Pascasarjana Institut Pertanian Bogor., Bogor. 
Tulungen J. et al. 2002. Panduan Pembentukan dan pengelolaan Daerah Perlindungan Laut Berbasis Masyarakat. Proyek Pesisir., Jakarta.

UNESCO. 2000. Reducing Megacity Impacts on the Coastal Environment: Alternatif Livelihoods and Waste Management in Jakarta and Seribu Islands. Coastal Region and Small Island Paper 6. UNESCO., Paris.
Ward, T J, Heinemann, D and Evans, N 2001. The Role Of Marine Reserves as Fisheries Management Tools - a Review of Concepts, Evidence and International Experience. Bureau of Rural Sciences., Canberra. 